
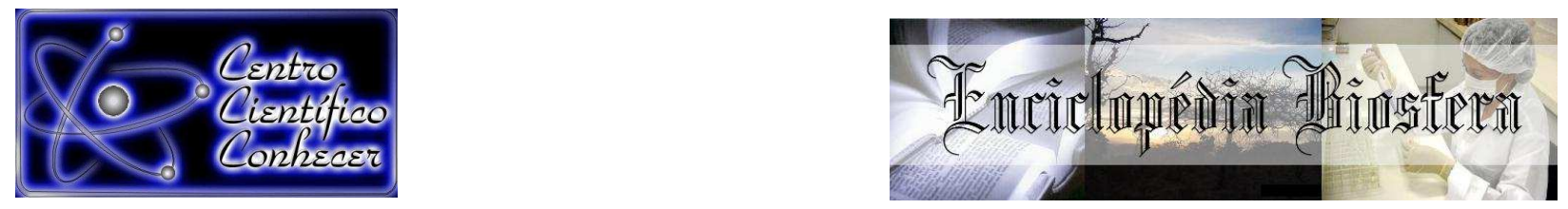

\title{
POSTURA CORPORAL DE UM OPERADOR NA OPERAÇÃO DE MARCAÇÃO DE LINHA PARA ENLEIRAMENTO DE BIOMASSA ENERGÉTICA
}

\author{
Ana Paula Micali Figueiredo ${ }^{1}$, Eduardo da Silva Lopes $^{2}$, Felipe Martins de Oliveira $^{3}$ \\ ${ }^{1}$ Mestre em Ciências Florestais pela Universidade Estadual do Centro-Oeste - \\ UNICENTRO, (anamicalli@hotmail.com) Irati, PR, Brasil \\ ${ }^{2}$ Professor Doutor do Departamento de Engenharia Florestal da UNICENTRO, \\ Irati, PR, Brasil \\ ${ }^{3}$ Discente do Curso de Doutorado em Ciências Florestais da Universidade Estadual \\ do Centro-Oeste - UNICENTRO, Irati, PR, Brasil
}

Recebido em: 08/04/2017 - Aprovado em: 10/06/2017 - Publicado em: 20/06/2017

DOI: 10.18677/EnciBio_2017A82

\begin{abstract}
RESUMO
Objetivou-se neste estudo avaliar a postura corporal do trabalhador na operação de marcação de linha para enleiramento de resíduos florestais, visando a melhoria das condições de conforto, segurança e saúde. O estudo foi realizado em uma empresa localizada no município de Arapoti, PR, na operação com um trator-subsolador que realizava a marcação das linhas para a formação de leiras a cada $50 \mathrm{~m}$. A avaliação da postura corporal foi realizada por meio de filmagens do posto de trabalho, identificando as posturas típicas adotadas pelo trabalhador, sendo os dados analisados pelo método RULA (Rapid Upper-Limb Assessment) e REBA (Rapid Entire Body Assessment). Os resultados mostraram a existência de quatro posturas típicas adotadas pelo trabalhador nas atividades parciais de marcação de linha propriamente dita e manobra, todas com problemas posturais. As piores posturas foram relacionadas com a torção do tronco e do pescoço em mais de $25 \%$ do tempo do ciclo operacional, necessitando adotar melhorias no posto de trabalho, como instalação de câmeras voltadas para a haste de subsolagem. A manutenção da mesma postura sentada por longos períodos de tempo também se mostrou prejudicial, podendo ser corrigida pela introdução de pausas e alternância de posturas, de forma a evitar futuras tensões musculares, fadiga e dores.
\end{abstract}

PALAVRAS-CHAVE: Avaliação postural; Ergonomia; Implantação florestal.

\section{AN OPERATOR'S BODY POSTURE IN THE OPERATION OF LINE MARKING FOR FOREST ENERGY BIOMASS}

\begin{abstract}
The objective of this study was to evaluate the worker's body posture in the line marking operation for disposal of forest residues, aiming at improving comfort, safety and health conditions. The study was carried out in a company located in the city of Arapoti, Parana State, Brazil, in an operation with a tractor-subsoiler that made the marking of the lines for formation of 50-meter-spacing residues mounts. The evaluation of body posture was performed by filming the work station, identifying the
\end{abstract}


typical postures adopted by the worker, and the data were analyzed by both Rapid Upper Limb Assessment (RULA) and Rapid Entire Body Assessment (REBA) methods. The results showed the existence of four typical postures adopted by the worker in the partial activities of line marking and driving, all with postural problems. The worst postures were related to twisting of trunk and neck in more than $25 \%$ of the time of the operational cycle, needing to adopt improvements in the workstation, like installation of cameras directed to the subsoiling tool. The maintenance of the same posture seated for long periods of time was also harmful, and can be corrected by the introduction of pauses and alternation of postures, in order to avoid future muscular tensions, fatigue and pains.

KEYWORDS: Postural evaluation; Ergonomics; Forest implantation.

\section{INTRODUÇÃO}

Apesar dos diversos avanços tecnológicos que ocorreram no setor florestal nas últimas décadas, pouco tem sido desenvolvido em termos de tecnologia para as operações silviculturais quando esta é comparada com a tecnologia de colheita da madeira. Na implantação florestal, por exemplo, muitas operações são realizadas por métodos semimecanizados, demandando maior contingente de mão de obra e expondo os trabalhadores a condições ergonômicas inapropriadas (BRITTO et al, 2014).

Dentre os problemas mais comuns verificados nas operações silviculturais está a manutenção de posturas inadequadas para a saúde e a segurança do trabalhador, as quais também influenciam seu conforto na realização do trabalho. IIDA \& GUIMARÃES (2016) relatam que períodos prolongados de exposição a essas posturas podem acarretar no aparecimento de dores e fadiga (sonolência, falta de disposição, dificuldade de pensar, diminuição da atenção, lentidão, perdas de produtividade em atividades físicas e mentais). Desta forma, tais situações poderão ocasionar transtornos à saúde dos operadores e comprometer suas capacidades física e psíquica (SILVA et al., 2013).

$\mathrm{Na}$ implantação florestal é comum verificar os trabalhadores com a coluna torcida ou realizando movimentos repetitivos, assumindo posturas incorretas durante a jornada de trabalho que poderão prejudicar a saúde (FIEDLER et al., 2003). Isto força as empresas a desenvolverem equipamentos adaptados para diferentes situações, como é o caso da operação de marcação de linha com trator para enleiramento de resíduos florestais.

Como esta é uma operação necessária para a reforma do talhão, pois contribui para deixar o solo em melhores condições para a subsolagem das linhas de plantio, é crucial que a ergonomia faça parte do planejamento, auxiliando no reconhecimento dos riscos a que os operadores estão submetidos no ambiente de trabalho. Sendo assim, este trabalho objetivou avaliar as posturas típicas adotadas pelo trabalhador no posto de trabalho em um trator na operação de marcação de linha para enleiramento de resíduos florestais, visando a melhoria das condições de conforto, segurança e saúde do trabalhador florestal.

\section{Área de estudo}

\section{MATERIAL E MÉTODOS}

Esta pesquisa foi realizada em uma empresa florestal localizada no município

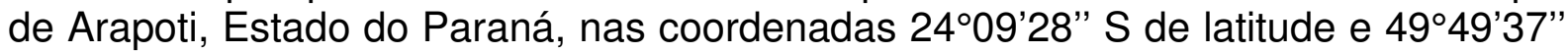
W de longitude e altitude média de 771 metros. O clima predominante na região de 
estudo é caracterizado por verões quentes, geadas pouco frequentes e tendências de concentração de chuvas nos meses de verão, contudo sem estação seca definida, sendo classificado por Köppen-Geiger como subtropical - Cfa, com precipitação média anual entre 1400 e $1600 \mathrm{~mm}$, temperatura média no inverno de $18^{\circ} \mathrm{C}$ e no verão de $22^{\circ} \mathrm{C}$ (IAPAR, 2017).

\section{Caracterização da máquina e operação de marcação de linha}

A operação foi realizada pelo conjunto trator-subsolador (Figura 1). O trator estudado foi o de marca John Deere, modelo 7195J, com motor de potência nominal de 195 cv $(143,4 \mathrm{~kW})$, rodados de pneus com tração 4x4, o qual possuía um subsolador com haste negativa adaptado pela empresa, acoplado ao sistema de levante hidráulico.

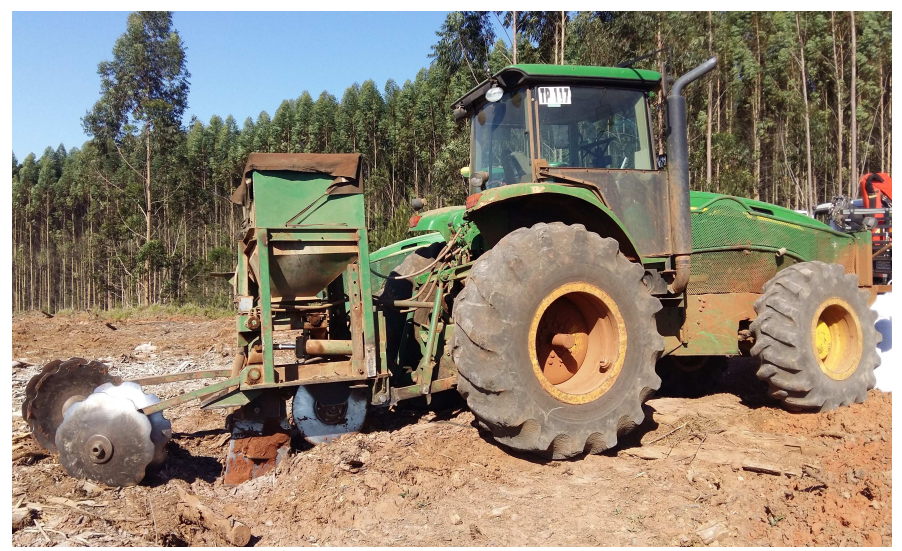

FIGURA 1. Conjunto trator-subsolador utilizado pelo operador. Fonte: Arquivo pessoal, (2016).

A marcação de linhas para o enleiramento de resíduos florestais foi realizada pelo implemento de subsolagem em intervalos de 50 metros, predeterminados de acordo com um aparelho GNSS (Global Navigation Satelite Systems) instalado no trator. Após esta operação, o skidder realizava o enleiramento dos resíduos para posterior subsolagem das linhas de plantio com distribuição simultânea de fertilização química, deixando o talhão em condições para receber as mudas e originar um novo plantio florestal.

O ciclo operacional da marcação de linha para enleiramento dos resíduos foi subdividido nos elementos parciais: Marcação de linhas (ML), considerada desde o início da inserção da haste do subsolador no solo para realização da subsolagem, finalizando com a retirada do implemento ao final da linha; e Manobra (MN), considerada do início da manobra no final de cada linha, finalizando com a inserção da haste do subsolador no solo para marcação da linha seguinte, a $50 \mathrm{~m}$ paralelamente à linha anterior. Os tempos não produtivos (interrupções pessoais, mecânicas, etc.) não foram contabilizados para a avaliação postural.

\section{Operador estudado}

A avaliação postural foi realizada em um operador do sexo masculino com idade de 28 anos, estatura de 1,85 m, massa corporal de $75 \mathrm{Kg}$ e experiência de quatro anos na atividade de marcação de linhas. $O$ operador foi selecionado pela empresa conforme a experiência na execução da operação e capacidade média de produtividade. Inicialmente, o operador recebeu esclarecimentos sobre a pesquisa 
por meio da assinatura do Termo de Consentimento Livre e Esclarecido (TCLE), em atendimento à Resolução n. 466/2012 do Conselho Nacional de Saúde do Ministério da Saúde (BRASIL, 2012) e à aprovação por um Comitê de Ética em Pesquisa (Parecer $\mathrm{n}^{0}$ 1.550.684).

\section{Avaliação postural no posto de trabalho}

A avaliação das posturas adotadas pelo operador foi realizada a partir de filmagens da operação em ambos os elementos parciais ML e MN. Foi utilizada uma câmera tipo DVR, marca $A C T I A$, com uma unidade gravadora com quatro canais e cartões de memória, que foram instaladas no interior da cabine do trator-subsolador (Figura 2). As câmeras foram orientadas de modo a captar as posturas típicas adotadas pelo operador durante a execução do trabalho.
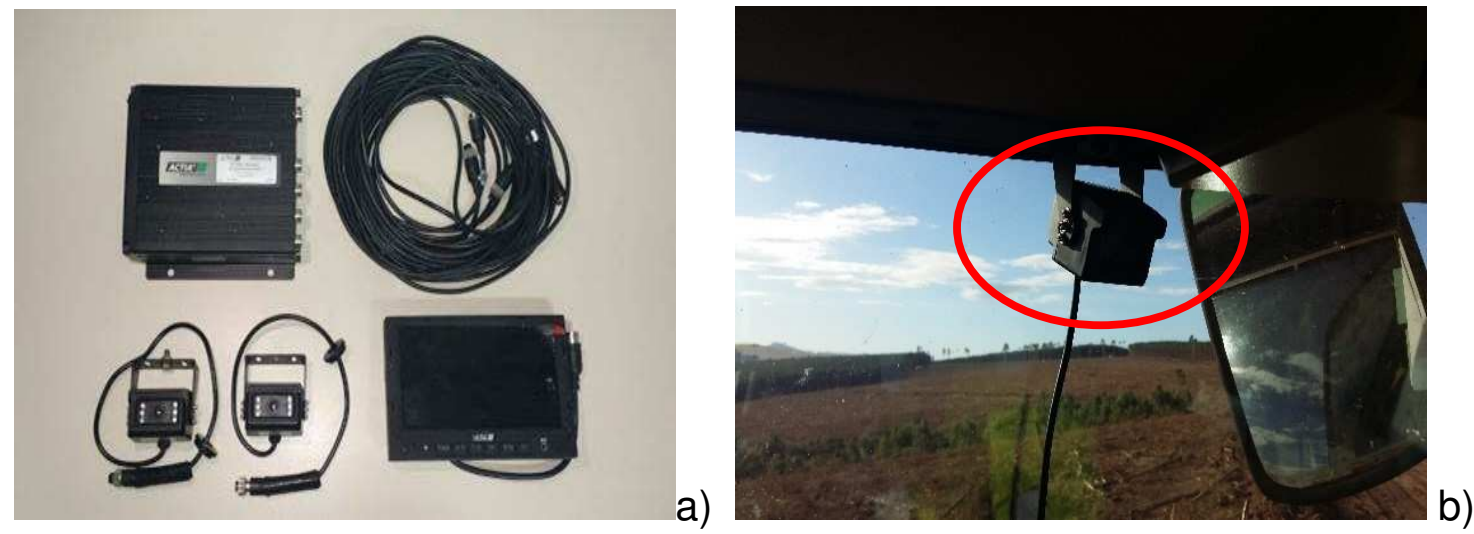

FIGURA 2. Equipamentos utilizados para a filmagem: a) Conjunto de câmera do tipo DVR; e b) Posição de instalação da câmera dentro da cabine do trator-subsolador.

Fonte: Arquivo pessoal, (2016).

Inicialmente foi realizado um estudo de tempos e movimentos para a operação de marcação de linhas pelo método de cronometragem de tempos contínuos (BARNES, 1977), com a finalidade de relacionar o tempo de permanência do operador em cada postura típica adotada definindo o número mínimo de observações necessárias para obtenção de um erro de amostragem máximo de 5\% ao nível de $95 \%$ de probabilidade. Para tal, foram utilizadas prancheta, formulário de campo e cronômetro centesimal.

Após a realização das filmagens, foram então selecionadas as posturas típicas adotadas pelo operador em cada atividade parcial do ciclo de trabalho da operação de marcação de linhas, as quais foram analisadas pelos métodos RULA e REBA. O método RULA - Rapid Upper-Limb Assessment possui foco na avaliação dos membros superiores, contemplando os distúrbios do grupo A (braços, antebraço e rotação dos punhos) e $B$ (pescoço, tronco e pernas) proposto por McATAMNEY \& CORLETT (1993) (Figura 3). 


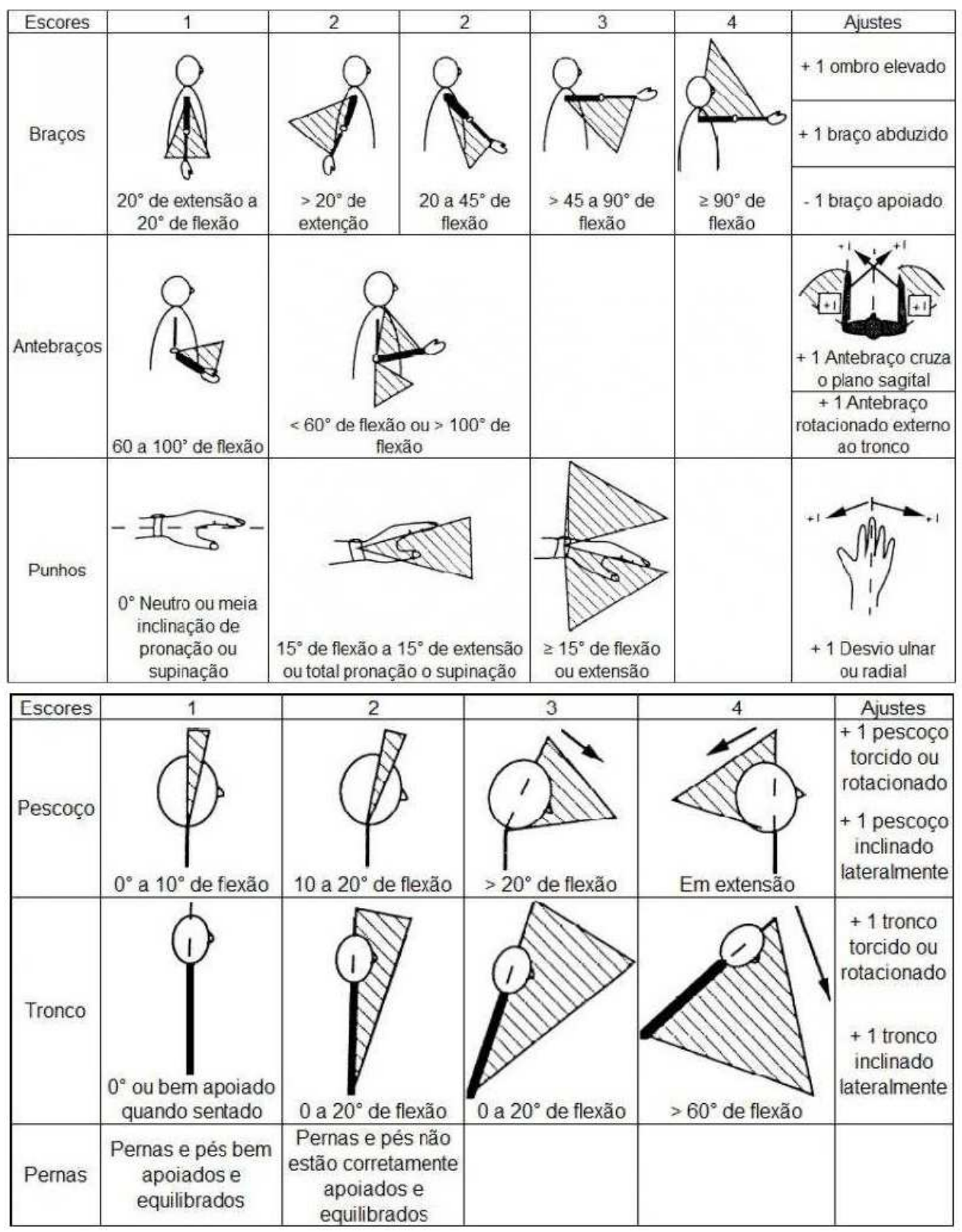

FIGURA 3. Escores dos segmentos corpóreos do método RULA.

Fonte: Adaptado de MCATAMNEY \& CORLETT (1993).

Após o processamento dos dados, obteve-se um escore final para cada postura típica adotada pelo operador nas atividades parciais de marcação de linha e manobra, conforme descrito na Tabela 1.

TABELA 1. Escore final método RULA

\begin{tabular}{|c|c|c|c|c|c|}
\hline Pontuação & Nível de ação & Intervenção & & & \\
\hline 1 ou 2 & 1 & $\begin{array}{l}\text { Postura aceitável se não for mantida } \\
\text { longos períodos }\end{array}$ & ou & repetida & por \\
\hline 3 ou 4 & 2 & $\begin{array}{l}\text { Deve-se realizar uma observação } \\
\text { necessárias mudanças. }\end{array}$ & e & podem & ser \\
\hline 5 ou 6 & 3 & $\begin{array}{l}\text { Deve-se realizar uma investigação } \\
\text { introduzidas mudanças. }\end{array}$ & e & devem & ser \\
\hline 7 ou mais & 4 & \multicolumn{4}{|c|}{ Devem ser introduzidas mudanças imediatamente. } \\
\hline
\end{tabular}

Fonte: MCATAMNEY \& CORLETT, 1993. 
O método REBA (Rapid Entire Body Assessment), desenvolvido por HIGNETT \& McATAMMEY (2000), contemplou a avaliação da atividade muscular estática adotada pelo corpo humano, as cargas manuseadas, as angulações do movimento, a repetitividade do trabalho e a qualidade da pega executada pelo trabalhador. O método é composto por dois grupos de membros do corpo humano, sendo A (tronco, pescoço e pernas) e B (braços, antebraços e punhos), conforme a Figura 4.

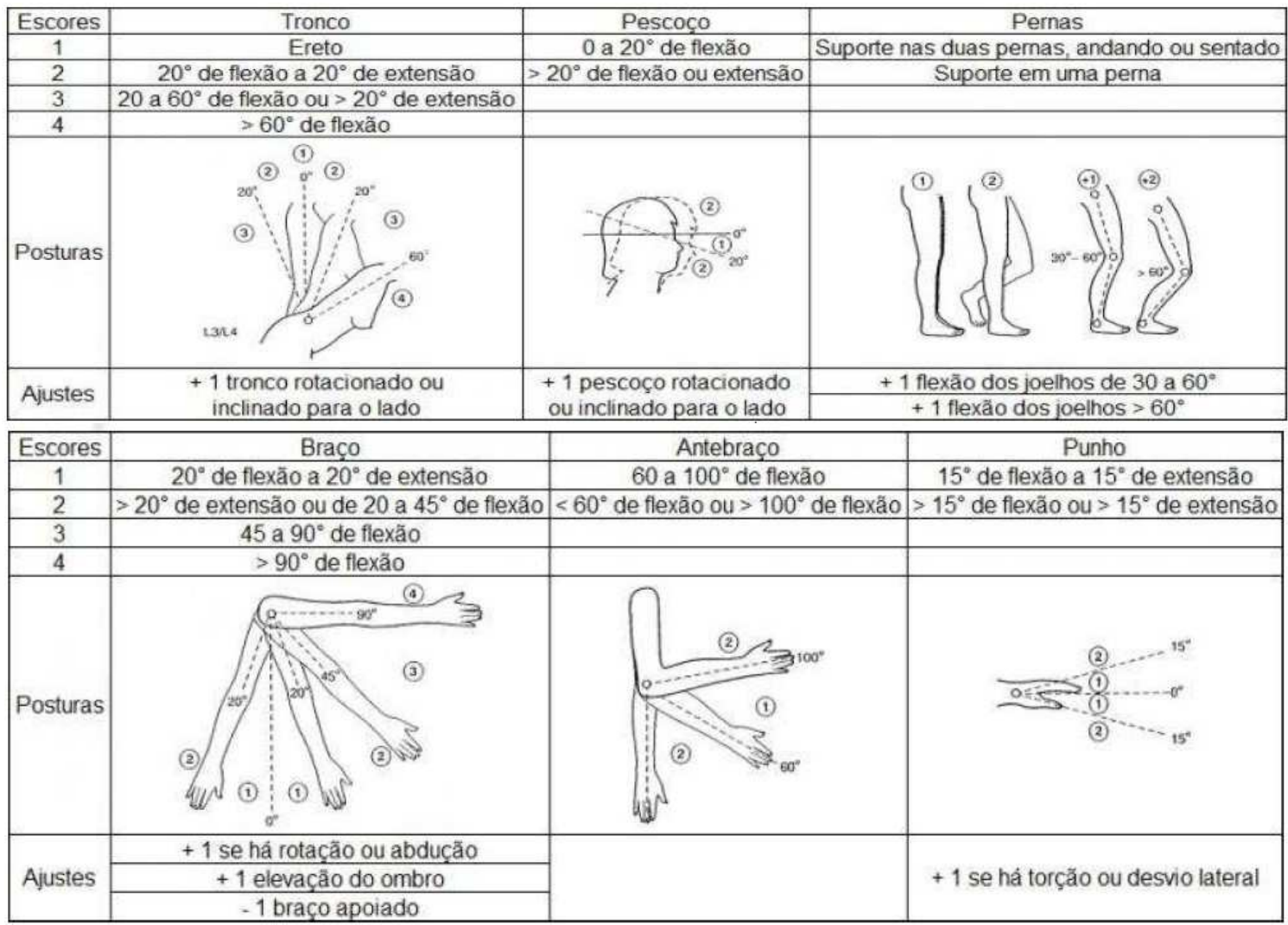

FIGURA 4. Escores dos segmentos corpóreos do método REBA. Fonte: Adaptado de HIGNETT \& MCATAMNEY, (2000).

Desta forma, por meio da pontuação obtida foram acrescentados dados em relação à qualidade da pega, carga manuseada e atividade (manutenção das posturas estáticas e movimentos repetitivos), posteriormente obtendo o escore final e os níveis de ação que permitiram identificar a intervenção necessária para cada postura típica adotada (Tabela 2 ).

TABELA 2. Resultados da avaliação com o método REBA

\begin{tabular}{cccl}
\hline Nível de ação & Pontuação & Nível de risco & \multicolumn{1}{c}{ Intervenção } \\
\hline 0 & 1 & Inexistente & Não é necessária \\
1 & 2 ou 3 & Baixo & Pode ser necessária \\
2 & 4 a 7 & Médio & Necessária \\
3 & 8 a 10 & Alto & Necessária o quanto antes \\
4 & 11 a 15 & Muito alto & Necessária imediatamente \\
\hline
\end{tabular}

Fonte: Adaptado de HIGNETT \& MCATAMNEY, (2000). 


\section{RESULTADOS E DISCUSSÃO}

Para a análise das posturas adotadas pelo operador na marcação de linhas obteve-se 39 ciclos operacionais que foram caracterizados por realizarem uma linha completa de marcação. O tempo médio para a realização do ciclo foi de 11,31 minutos para uma eficiência operacional de $80 \%$. Foi possível identificar duas posturas típicas adotadas pelo trabalhador em cada elemento parcial do ciclo. $\mathrm{Na}$ Tabela 3 estão demonstradas as posturas típicas adotadas pelo operador durante a execução da atividade marcação de linha para o enleiramento de resíduos e os respectivos resultados da avaliação postural.

TABELA 3. Posturas típicas adotadas pelo operador e resultados da avaliação postural na atividade de marcação de linhas.

\begin{tabular}{cccc}
\hline Postura \\
típica
\end{tabular}

A pior postura foi a ML2, realizada no elemento parcial de marcação de linha propriamente dita, caracterizada pela necessidade do operador olhar para trás a fim de conferir se a subsolagem estava sendo realizada de forma correta, impactada por travamentos eventuais da haste de subsolagem em resíduos deixados pela colheita. Esta foi considerada a pior postura adotada devido ao operador ter trabalhado com a coluna e o pescoço torcidos em $25,4 \%$ do tempo efetivo do ciclo operacional. Além 
disso, o método RULA (que dá enfoque para a avaliação de sobrecarga nos membros superiores) indicou que são necessárias investigações em breve, ou seja, além de necessitar de maior cuidado ergonômico, isto deve ser feito em um futuro não muito distante, devido ao risco físico que a manutenção desta postura oferece à saúde do trabalhador.

A postura MN2, realizada na operação parcial de manobra, possui as mesmas características que a postura $\mathrm{ML2}$, lesivas à saúde do trabalhador, entretanto atenuada pelo fato de acontecer em apenas $1,5 \%$ do tempo efetivo do ciclo operacional. Mesmo assim, ficou evidente que a postura do operador é inapropriada para o trabalho, precisando realizar mudanças para evitar problemas futuros, como tensões nos músculos lombares, fadiga e dores musculares.

Os projetos inadequados de assentos, comandos e postos de trabalho nas máquinas podem forçar o trabalhador a adotar posturas ocupacionais incorretas (IIDA \& GUIMARÃES, 2016). Isto foi observado na operação em questão, pois o trator foi originalmente projetado para o trabalho frontal, e não para a necessidade de torcer o tronco e o pescoço em mais de $25 \%$ do tempo da jornada de trabalho. A instalação de câmeras para a filmagem da haste de subsolagem pode ser uma alternativa viável de adequação do maquinário às necessidades biomecânicas que a operação impõe ao trabalhador.

Ambas as posturas ML1 e MN1, apesar de não apresentarem a severidade característica das demais, também foram diagnosticadas pelo método RULA como necessitadas de mudanças, devido à manutenção da mesma postura em longos períodos de tempo sentado. DUL \& WEERDMEESTER (2012) asseveram que não é adequado manter a mesma postura (mesmo que sentada) por um longo período de tempo, pois isto pode acometer dores localizadas agressivas tanto nos músculos como nas articulações.

PAINI et al. (2016), ao estudarem a postura corporal de um operador no carregamento mecanizado de madeira também observaram posturas desfavoráveis originadas tanto pela rotação de tronco e pescoço como pela manutenção da mesma postura por prolongados períodos de tempo na jornada de trabalho. COUTO (1995), explica que se o trabalho for executado por meio da adoção de posturas inadequadas este pode originar sérias implicações para a saúde e quanto mais a postura se afastar da neutra (próxima do centro de gravidade natural), mais exige esforço da musculatura e das articulações, podendo causar maior risco de doenças ocupacionais e lesões.

O método REBA, que avalia as posturas do corpo como um todo, forneceu o mesmo diagnóstico para as quatro posturas típicas, atestando que há a necessidade de providências a serem tomadas em todas. Pode-se dizer que ambos os métodos de avaliação postural verificaram problemas posturais em todos os elementos parciais do ciclo operacional, entretanto o método RULA, que analisa com maior profundidade os membros superiores, indicou mais severidade nas posturas em que o operador necessita olhar para trás.

A ergonomia possui foco principal na saúde e segurança do trabalhador, mas muitos estudos têm sido desenvolvidos para demonstrar que as melhorias ergonômicas atuam de forma positiva tanto para a saúde, segurança e conforto do trabalhador, como para a melhoria do desempenho na operação (GUIMARÃES et al., 2015; SOUZA et al., 2015). Sendo assim, devem ser realizadas mais investigações na operação estudada, pois além dos benefícios ao trabalhador, a operação como um todo pode se tornar mais sustentável e produtiva. 
Por fim, a operação de marcação de linhas para enleiramento de resíduos florestais carece da adoção de medidas ergonômicas, e além da já citada instalação de uma câmera junto ao subsolador que permita a visualização do trabalho diretamente da cabine, podem ser introduzidas pausas de recuperação intercaladas com ginástica laboral e mudanças posturais durante a jornada de trabalho, orientadas por meio de treinamento aos operadores.

\section{CONCLUSÕES}

- Todas as posturas típicas observadas na operação de marcação de linhas para enleiramento de resíduos mostraram-se inadequadas à saúde do operador e podem causar lesões e perda de produtividade mostrando, assim, a necessidade de melhorias nos métodos de trabalho.

- As piores posturas foram relacionadas com a torção de tronco e pescoço quando foi necessário que o operador olhasse para trás. Outras posturas não tão severas foram relacionadas com a permanência do trabalhador por um longo período de tempo na posição sentada.

- A instalação de câmeras de monitoramento, a adoção de pausas de recuperação e ginástica laboral distribuída durante a jornada de trabalho poderão contribuir para a melhoria das posturas adotadas pelos operadores florestais.

\section{AGRADECIMENTOS}

Os autores agradecem à empresa pelo apoio e disponibilização da área de estudo e à Capes pelo apoio financeiro.

\section{REFERÊNCIAS}

BARNES, R. M. Estudo de movimentos e de tempos: projeto e medida do trabalho. São Paulo: Edgard Blücher, 1977. 635 p.

BRASIL. Conselho Nacional de Saúde. Resolução $n^{\circ}$ 466, de 12 de dezembro de 2012. Aprova normas regulamentadoras de pesquisas envolvendo seres humanos. Brasília: Diário Oficial da União, Seção I, p. 59, jun/2013.

BRITTO, P. C.; LOPES, E. S.; LAAT, E. F.; FIEDLER, N. C. Avaliação biomecânica de trabalhadores de diferentes estaturas nas atividades de Plantio e Adubação Florestal. Scientia Forestalis, Piracicaba, v.42, n.102, p.191-196, 2014.

COUTO, H. A. Ergonomia aplicada ao trabalho: o manual técnico da máquina humana. Belo Horizonte: Ergo Editora, 1995. v. 1, 353 p.

DUL, J.; WEERDMEESTER, B. Ergonomia prática. 3ed.São Paulo: Edgard Blucher. 2012. 163p.

FIEDLER, N. C.; MENEZES, N. S.; AZEVEDO, I. N. C.; SILVA, J. R. M. Avaliação biomecânica dos trabalhadores em marcenarias no Distrito Federal. Ciência Florestal, Santa Maria, v.13, n.2, p.99-109, 2003. Disponível em: < http://dx.doi.org/10.5902/198050981746> doi: 10.5902/198050981746

GUIMARÃES, L. B. M.; ANZANELLO, M. J.; RIBEIRO, J. L. D.; SAURIN, T. A. Participatory ergonomics intervention for improving human and production outcomes 
of a Brazilian furniture company. International Journal of Industrial Ergonomics, v. 49, p. 97-107, set/2015. Disponível em: <http://dx.doi.org/10.1016/j.ergon.2015.02.002>. doi:10.1016/j.ergon.2015.02.002

HIGNETT, S.; McATAMNEY, L. Rapid entire body assessment (REBA). Applied Ergonomics, v. 31, n. 2, p.201-205. 2000. Disponível em: <http://dx.doi.org/10.1016/S0003-6870(99)00039-3>. doi:10.1016/S00036870(99)00039-3

IAPAR - Instituto Agronômico do Paraná. Cartas climáticas do Paraná. Disponível em: <http://www.iapar.br/modules/conteudo/conteudo.php?conteudo=863> Acesso em 29 mar. 2017.

IIDA, I.; GUIMARÃES, L.B.M. Ergonomia: Projeto e Produção. 3ed. São Paulo: Edgard Blücher, 2016. 850p.

MCATAMNEY, L.; CORLETT, E. N. RULA: a survey method for the investigation of world-related upper limb disorders. Applied Ergonomics, v. 24, n. 2, p. 91-99, 1993. Disponível em: <http://dx.doi.org/10.1016/0003-6870(93)90080-S> doi:10.1016/0003-870(93)90080-S

PAINI, A.C.; LOPES, E.S.; OLIVEIRA, F.M. Postura corporal de operador no carregamento mecanizado de madeira - estudo de caso. Enciclopédia Biosfera, Goiânia, v.13, n.23; p.962-974, 2016. Disponível em: <http://www.conhecer.org.br/enciclop/2016a/agrarias/postura\%20corporal.pdf> doi: 10.18677/Enciclopedia_Biosfera_2016_083

SILVA, E.P.; MINETTE, L.J.; SOUZA, A.P.; MARÇAL, M.A.; SANCHES, A.L.P. Fatores organizacionais e psicossociais associados ao risco de LER/DORT em operadores de máquinas de colheita florestal. Revista Árvore, Viçosa, v. 37, n. 5, p.889-895, 2013. Disponível em: <http://dx.doi.org/10.1590/S010067622013000500011> doi: 10.1590/S0100-67622013000500011

SOUZA, A. P.; DUTRA, R. B. C.; MINETTE, L. J.; MARZANO, F. L. C.; SCHETTINO, $\mathrm{S}$. Metas de produção para trabalhadores de corte florestal. Revista Árvore, Viçosa, v.39, n.4, p.713-722, 2015. Disponível em: <http://dx.doi.org/10.1590/010067622015000400014> doi: 10.1590/0100-67622015000400014 